First Peoples Child \& Family Review

A Journal on Innovation and Best Practices in Aboriginal Child Welfare Administration,

Research, Policy \& Practice

\title{
Culturally Sensitive Approaches to Research on Child Development and Family Practices in First Peoples Communities
}

\author{
Kelly E. McShane and Paul D. Hastings
}

Volume 1, Number 1, 2004

URI: https://id.erudit.org/iderudit/1069583ar

DOI: https://doi.org/10.7202/1069583ar

See table of contents

Publisher(s)

First Nations Child and Family Caring Society of Canada

ISSN

1708-489X (print)

2293-6610 (digital)

Explore this journal

Cite this article

McShane, K. \& Hastings, P. (2004). Culturally Sensitive Approaches to Research on Child Development and Family Practices in First Peoples Communities. First Peoples Child \& Family Review, 1(1), 33-48. https://doi.org/10.7202/1069583ar

\section{Article abstract}

This paper focuses on highlighting some of the concerns that need to be addressed in conducting psychological research with First Peoples children and families. The extensive literature on healthy child development and family practices in Caucasian families is contrasted with the limited perspective on First Peoples families. We suggest that this is, in part, due to an unnecessary focus on problem behaviours of children from First Peoples communities. We contend that it is imperative for developmental psychologists to adopt a new perspective, by acknowledging the strengths and competencies of First Peoples families, and using more culturally-sensitive approaches to working with First Peoples.
Copyright (C Kelly E. McShane, Paul D. Hastings, 2004
This document is protected by copyright law. Use of the services of Érudit (including reproduction) is subject to its terms and conditions, which can be viewed online.

https://apropos.erudit.org/en/users/policy-on-use/ 


\section{Abstract}

This paper focuses on highlighting some of the concerns that need to be addressed in conducting psychological research with First Peoples children and families. The extensive literature on healthy child development and family practices in Caucasian families is contrasted with the limited perspective on First Peoples families. We suggest that this is, in part, due to an unnecessary focus on problem behaviours of children from First Peoples communities. We contend that it is imperative for developmental psychologists to adopt a new perspective, by acknowledging the strengths and competencies of First Peoples families, and using more culturally-sensitive approaches to working with First Peoples.

\section{Culturally Sensitive Approaches to Research on Child Development and Family Practices in First Peoples Communities}

\author{
Kelly E. McShane and Paul D. Hastings*
}

\section{Introduction}

In traditional psychological models primary responsibility for encouraging their children to adopt the values of society and facilitating their children's optimal social and emotional development (Grusec \& Ungerer, 2003). A great deal of research has examined the familial influences on children's successful integration into broader social and academic spheres, but the vast majority of this research has been conducted by academics trained in Western scientific traditions and working with Anglophone Caucasian families. Recently, developmental psychologists have become increasingly interested in studying family relationships and children's development of socialization, parents are given the of competence in non-majority cultures, although little of this research has been done with families from Canada's First Peoples. The lack of research on the relations between parenting and children's competence in the First Peoples is not simply due to a lack of research on First Peoples families in general. Indeed there are many published studies, but this literature is disproportionately focused on children's development of problems. Perhaps this bias has been motivated by a legitimate concern and desire to help those children and families experiencing distress. Some First Peoples children and youth do have serious mental health problems, and obtaining access to appropriate services for those children is a serious issue. However,
*Authors' note: Support for researching this paper came from a Social Sciences and Humanities Research Council of Canada Doctoral Fellowship to the first author. The authors would like to thank Dr. Lucie Nadeau and Dr. Ann Macaulay for their thoughts on a number of research issues that contributed to the proposals presented in this paper. The comments of two anonymous reviewers are also acknowledged. 
The lack of research on effective socialization in First Peoples families has contributed to an absence of information on the normative healthy development of First Peoples children. the reality is that, like children and youth in the majority culture, most children and youths from First Peoples communities do not have psychosocial problems that limit their abilities or competence (Gotoweic \& Beiser, 1993; MacMillan, Welsh, Jamieson, Crawford, \& Boyle, 2000). Why, then, have developmental psychologists overlooked this fact and failed to examine the strengths of First Peoples families that support their children's competent development?

We contend that one reason why this knowledge gap has arisen is from illguided attempts to import the standard research procedures of Western social science disciplines, without regard for the cultural models and practices guiding communication and socialization in First Peoples communities. The lack of research on effective socialization in First Peoples families has contributed to an absence of information on the normative healthy development of First Peoples children. The success of Western-based approaches to treatment may be hampered by this limited understanding of cultural differences. By identifying positive and adaptive aspects of socialization, we will have a more accurate and complete understanding of the experiences of First Peoples families, and this information can be used to support the minority of First Peoples families in which children do have problems. Therefore, the goals of this paper are to instill readers with an awareness of culturally-sensitive approaches to research with First Peoples, and to underscore the importance of examining strengths of First Peoples families, instead of overlooking them.

\section{Healthy Psychosocial Development: Effective Parenting for Positive Growth}

Competence is generally used to describe children's healthy psychosocial development. Competence is demonstrated in a number of ways by children (Masten \& Coatsworth, 1998; Saarni, 1999).
Competent children feel good about themselves, adjust well to new situations and challenges, are typically happy, value their friendships and involvement with peers, and are successful in their scholastic endeavours. They express their emotions and desires in socially acceptable ways, rather than becoming frustrated or confrontational. They are empathic and demonstrate good problem-solving skills with their peers, attempting to find prosocial solutions to disagreements rather than resorting to aggression.

Caregivers, and more specifically parents, have most often been identified as having the greatest influence on children's competent psychosocial development. The foundations of competent development are established in the caregiver's relationship with her or his infant (e.g., Maccoby \& Martin, 1983). Effective parenting of infants is characterized as sensitive to the needs of infants and responsive to infants' cues (Weinfield, Sroufe, Egeland, \& Carlson, 1999). In other words, these parents recognize what their infants' needs are, when their infants' require their care, and how to best provide this care to their infants (Ainsworth, Blehar, Waters, \& Wall, 1978; Main \& Solomon, 1990). This approach to infant care bestows infants with a secure attachment to their parents, such that infants feel safe, supported, and prepared to learn about the world.

Although secure attachment has been considered a cornerstone of the subsequent development of social and emotional competence, it is not sufficient, nor does it represent the sole contribution of parents. A variety of features of child-rearing of preschoolers, school-aged children and youth have been identified as supporting healthy psychological functioning. Some of the most frequently studied aspects of child-rearing include limit-setting: establishing rules and guidelines for children's behaviour; modeling: engaging in the kinds of behaviours parents want to encourage in their children; reasoning: explaining why rules are in place, 


An authoritative style of
child-rearing, which is
both demanding (rules,
limits, and expectations)
and responsive (warmth,
negotiation and reasoning)
is typically associated
with children's healthy
psychosocial development
and competence.

An authoritative style of child-rearing, which is limits, and expectations) and responsive (warmth, negotiation and reasoning) is typically associated with children's healthy and competence. behaviours are necessary, and what the consequences of children's actions are; negotiating: being flexible and allowing children to contribute to decisions; showing warmth: being affectionate and caring; and monitoring: being aware of a child's where-abouts, activities, and friendships.

Parents who engage in limit-setting have children who engage in more prosocial behaviours with others (Cowan, Cowan, Schulz, \& Heming, 1994) and perform better in school (Gray \& Steinberg, 1999; Paulson, 1994). Parental limit-setting also is linked to lower aggression and delinquency (Denham, Workman, Cole, Weissbrod, Kendziora, \& Zahn-Waxler, 2000), and anxiety and depression (Mattanah, 2001) in children. Parents who model caring and concerned behaviour toward others (e.g., are helpful and giving) have children who are more likely to react similarly when they see others in distress (Radke-Yarrow \& ZahnWaxler, 1984). Parents who use reasoning and negotiation when interacting and disciplining their children have children who demonstrate competent methods of self-expression (Kuczynski \& Kochanska, 1990). Parental warmth is associated with greater prosocial behaviour and greater academic competence (MacDonald, 1992; Paulson, 1994). Parents who are effective at monitoring have children who are less antisocial, oppositional, and likely to use alcohol or drugs (Dishion \& Patterson, 1997; Patterson, Reid, \& Dishion, 1992).

Conversely, there are also a range of child-rearing behaviours that are considered less adaptive, as they are associated with undesirable outcomes in children and youth. For instance, a consistent finding across the literature is that parents' use of corporal punishment, including slapping, spanking, and more severe physical punishments, is associated with aggression, delinquency, depression, and other mental health problems (MacMillan et al., 1999; Strauss \& Donnelley, 1994). Other aspects of child-care may become maladaptive if they are used inappropriately or excessively. For example, although all parents need to shield their children from danger, parents who are over-protective and unnecessarily restrict their children's experiences tend to foster greater anxiety, shyness and dependence in their children (Barber \& Harmon, 2002; McShane, 2003; Rubin, Burgess, \& Hastings, 2002).

Of course, different parenting behaviours do not get used in isolation from each other. Children experience most of these kinds of child-care behaviours to varying degrees. Many researchers look at the pattern of parents' use of varying behaviours in order to characterize parents' general or overall styles of raising their children (Baumrind, 1971). These styles are often described as varying along two key underlying dimensions: demandingness and responsiveness (Maccoby \& Martin, 1983). An authoritative style of childrearing, which is both demanding (rules, limits, and expectations) and responsive (warmth, negotiation and reasoning) is typically associated with children's healthy psychosocial development and competence. This has been shown in children's higher self-esteem, social and moral maturity, caring and helpfulness toward others, involvement in school learning, academic achievement and educational attainment (e.g., Hastings, Zahn-Waxler, Robinson, Usher, \& Bridges, 2000; Steinberg, Lamborn, Darling, Mounts, \& Dornbusch, 1994). Conversely, children who have psychosocial problems or lower levels of competence most often are raised by parents who use nonauthoritative styles of child-rearing. These styles include authoritarian (demanding but not responsive), permissive (responsive but not demanding), and neglectful or uninvolved (neither demanding nor responsive).

First Peoples Families: Limited Perspective on Psychosocial 


First Peoples and
Caucasian parents
hold many of the same
values with respect to the
psychosocial outcomes
they seek to foster in
their children. These
include family connection,
autonomy, friendships,
maturity, cooperation, and
responsibility. But there are
also some differences in
values.

First Peoples and

Caucasian parents

hold many of the same

psychosocial outcomes

they seek to foster in

their children. These

include family connection, autonomy, friendships, maturity, cooperation, and also some differences in values.

\section{Development}

The above detailed theories and research have been derived almost exclusively from Caucasian children and families. Furthermore, the majority of researchers examining children's competence and child-rearing practices are from a Western cultural background and have received their academic training from Western institutions. It is only recently that researchers have examined these research areas in non-Western cultures. Researchers have recognized that children develop within a complex system of relationships affected by numerous levels of the surrounding environment, one of which is the cultural milieu (Bronfenbrenner, 1979, 1989, 1993). Specifically, culture provides the broader context within which parents form their beliefs about which characteristics should be valued in children and how to promote those characteristics. Children also learn to interpret the meaning of parents' approaches to childrearing according to the standards of their culture.

This acknowledgement of culture's role in socialization has spurred research examining features of child-rearing in different cultures. It has quickly become apparent that the patterns of associations between child-rearing practices and children's competence in Caucasian Canadian families (described above) are often different from those in non-majority culture families (e.g., Carson, Chowdhury, Perry, \& Pati, 1999; Jambunathan \& Counselman, 2002). For instance, studies examining Caucasian Canadian and Chinese families have found that parents' response to children's anxiety can have vastly different effects on children's competence. Chen, Hastings, Rubin, Chen, Cen, and Stewart (1998) found that in Caucasian families, parents feel negatively toward and are rejecting of, their children's anxious symptoms. This pattern is not seen in mainland Chinese families; these parents are more accepting of children's anxiety and feel better about anxious children.
Over time, Chinese children's anxious symptoms recede and social competence improves, whereas anxiety in Caucasian Canadian and American children tends to be more stable and associated with social difficulties (Chen, Li, Li, Li, \& Liu, 2000). This suggests that although it might be possible to measure the same childrearing characteristics across cultures, their relations to children's competence should not be assumed to be the same in different cultures.

In terms of First Peoples families, there has been limited work to date examining families and their role in healthy psychosocial development. It has been suggested that parenting values and attitudes of First Peoples are similar to those of Caucasian parents, although they differ in the degree to which these attitudes are translated into actual rearing of children (Glover, 2001). First Peoples and Caucasian parents hold many of the same values with respect to the psychosocial outcomes they seek to foster in their children. These include family connection, autonomy, friendships, maturity, cooperation, and responsibility. But there are also some differences in values. In the United States, traditional First Peoples values can include: generosity; respect for elders; respect for all creation; harmony, and non-interference (Deyhle \& LaCompte, 1999; Glover, 2001; Kallam \& Coser, 1994). First Peoples also differ in how they try to promote these healthy outcomes. Research with First Peoples in the United States has found that these families rely heavily on modelling and storytelling as vehicles of teaching or socialization (Deyhle \& LaCompte, 1999; Glover, 2001; Kallam \& Coser, 1994). In response to children's misbehaviours, common discipline strategies include power assertion, love withdrawal, inductive discipline, shame or embarrassment (Hoffman, 1977). A feature that appears to be unique to First Peoples is the dispensing of punishment by family members other than parents: such as aunts, uncles or grandparents. The goal of this 
Caucasian children are reared in a child-centered world, where parents expect them to accomplish tasks appropriate for their age. This contrasts with American Indian children who are reared in an adultcentered world, where they are encouraged to master adult tasks (e.g., responsibility for self-care). involvement of other family members in disciplinary actions is to protect the bond of love between parents and children, and also to reinforce the extended family's involvement in the child's day-to-day upbringing (LaFromboise \& Low, 1998).

One of the most striking differences in general parenting approaches between First Peoples and Caucasian parents is best described below:

The dominant culture often shows concern about the relative freedom given to a Native American child and the apparent lack of parental concern about the child's behavior. What appears as excessive permissiveness or indulgence, however, may consist of allowing children to develop in a healthy way. Autonomy is highly valued, and children are allowed to make their own decisions and operate semi-independently at an early age with the freedom to experience natural consequences (italics added; p. 218; Glover, 2001).

Supporting competent development is the specific goal underlying this technique. Parents and researchers from outside First Peoples communities may not see this technique as supporting that goal, but this difference in perspective reinforces the over-arching role culture plays in establishing the meaning and effects of parental actions. Some research has examined the links between childrearing attitudes and practices, and children's competence in First Peoples families. The larger extended family, increased time spent with tribal elders, and increased frequency of activities involving the entire family have been associated with a decreased likelihood of Ojibway adolescents being involved in delinquent activities (Zitzow, 1990). First Peoples children who are raised in a warm, accepting, nurturing environment exhibit more positive social skills (Rohner, Chaille, \& Rohner, 1980), similar to what has been observed with Caucasian families. The emphasis on self-reliance and autonomy by American Indian parents seems to promote an early emergence of developmental milestones; including dressing oneself, and doing regular chores (Miller, 1979, as cited in Joe \& Malach, 1992). Caucasian children are reared in a child-centered world, where parents expect them to accomplish tasks appropriate for their age. This contrasts with American Indian children who are reared in an adultcentered world, where they are encouraged to master adult tasks (e.g., responsibility for self-care).

Another interesting link between the emphasis on autonomy and children's competence comes from an unlikely place: parents' views of special needs children. Connors and Donnellan (1998) conducted a research study to examine Navajo views on disabled children. This information was gathered during an anthropological research study that was conducted at a residential facility for exceptional First Peoples children on the Navajo Nation, in the United States. This research was approached from a participant-observer perspective, whereby the researchers fully immersed themselves in the Navajo culture to the greatest extent possible in order to understand and document the culture's unique values and social processes about disabled children. The families selected for this research included at least one child who was labelled as autistic or mentally retarded by Western psychologists, and who was in residence at the facility. Connors and Donnelan (1998) noted that:
A great deal of permissiveness is given to Navajo children until the age of six or seven and this pervasive cultural child-rearing practice helps to explain the tolerance accorded to the clients with autism and those behaviors that are perceived to approximate notions of social competence (p. 175).

The authors go on to state that this notion of 'permissiveness' applies to physically handicapped children as well. These children are considered children, not in a helpless sense, but rather in a 'becoming persons' sense. This tolerance 
The prevalence of resilience, attaining healthy developmental outcomes despite the experience of adversity, points to the adaptability and tenacity of humans, and highlights the truism that problems are the exception, rather than the rule, of development. for and acceptance of individuality also makes Navajos less inclined to identify behaviours as 'problems' and more likely to view them 'characteristics' (Connors \& Donnellan, 1998). Although no research exists on how these views influence parenting practices, it is known that Navajo parents are reluctant to segregate or isolate children with disabilities. It is also known that this acceptance fosters a more relaxed attitude toward the role of the disabled child in the Navajo family structure. Thus, it is conceivable that this greater integration leads to more natural and healthy development in those children. Connors and Donnellan (1998) conclude that "this suggests that the traditional Navajo culture provides flexibility and resiliency in the face of disability that makes mental and emotional adjustments somewhat easier for the families to bear" (p. 179).

Clearly, this small collection of studies supports the proposition that effective and adaptive socialization practices of the First Peoples promote competence and healthy psychosocial development in their children. Both the value system of the First Peoples culture, and the child-rearing attitudes and behaviours of parents and extended family members, may confer advantages to children of the First Peoples. However, it is equally apparent that there is a dearth of empirical investigations on the links between socialization and competent development in the First Peoples. The more extensive literature on psychosocial problems needs to be balanced by more studies of typical, normative, healthy family functioning and child development.

In the remainder of this paper, we make several suggestions for ways in which developmental psychologists can begin to redress past oversights. These include the adoption of a different theoretical model or framework, the utilization of more sensitive, culturallyappropriate methodologies for learning about socialization and development in First Peoples, and novel approaches to initiating and pursuing the research process.

\section{Resilience: Focusing on the Positives}

Thirty years ago, a few leading developmental scientists began to draw researchers' and clinicians' attention to the fact that many, perhaps most, children raised in circumstances of hardship and adversity do not develop psychological problems or psychiatric disorders (e.g., Garmezy, 1974, Rutter, 1979). Despite experiencing economic deprivation, homelessness, social discrimination or other risks and disadvantages, these individuals develop well, attaining competence and health, and accomplishing relevant developmental social, academic, and occupational milestones. The prevalence of resilience, attaining healthy developmental outcomes despite the experience of adversity, points to the adaptability and tenacity of humans, and highlights the truism that problems are the exception, rather than the rule, of development. Researchers' investigations into the factors that predict or support resilience have revealed that resilient children are not extraordinary; they are ordinary (Masten, 2001). If children have intact neurocognitive functioning (e.g., no evidence of neurological injury) and supportive, involved parents, they are likely to survive even seriously adverse circumstances without being scarred.

Most of the research on resilience has been conducted with lower-income, visible minority groups in the United States. It is important to note, however, that epidemiological studies of the First Peoples indicate that healthy psychosocial development is the norm in these communities as well (e.g., Gotowiec \& Beiser, 1993; MacMillan et al., 2000). Given the low average annual income of Canada's First Peoples families, the number of First Peoples families living in sub-standard housing, the number of First Peoples communities located in 
In most cultures parents are the primary caregivers. However, in First Peoples families the extended family plays a large role in raising children. Kinship, emphasizing the interconnectedness of many family members and even non-familial community members, is one of the fundamental traditional values of First Peoples. remote locales with limited access to services, and the enduring prejudices held toward First Peoples by many in Canada's majority culture (Joe \& Malach, 1992; Strauss, 1995), it would be reasonable to state many of the children of the First Peoples are being raised under conditions of risk. Thus, the fact that most of these children do not show evidence of marked psychosocial difficulties is evidence that, like children from other communities, they are resilient.

Given the salient contributions of effective parenting to the resilient development of children in other cultural groups, it is likely that some of the qualities of parenting by First Peoples (e.g., modelling, involvement of other family and community members, maturity demands) protect children from the negative effects of adversity and hardship, and promote their healthy psychosocial development. By refocusing our theoretical perspective from models of illness and pathology (the effects of risk factors on the development of problems), to models of health and competence (the contributions of protective factors to the development of positive outcomes), developmental scientists can support effective parenting and resilient development in the First Peoples. Further, by accurately characterizing the ways in which First Peoples children show their competence, and identifying the family and cultural features that support this competence, we may be able to design new and culturally-meaningful ways to assist the minority of First Peoples families in which children are not manifesting resilience. Cooperative and proactive recommendations for child-rearing ("Try this; it has worked for your neighbours.") are likely to be more effective for helping families to overcome their troubles than prohibitive directions drawn from dissimilar experiences ("Don't do that because we've found it doesn't work.").

\section{New Directions for Our}

\section{Understanding of First Peoples}

We are now faced with the challenge of shifting our research focus with First Peoples families away from a negativeoutcome focus, to a competence and resilience focus. This shift will permeate through all levels of research, including topic, participants, measures, and process. Traditionally, most researchers have taken an epidemiological approach whereby groups of First Peoples are described on a broad variety of characteristics (e.g., age, gender, level of schooling, psychiatric problems), but any given characteristic is not examined in great depth. This has applied equally to examinations of children's problems and parents' socialization of children. Therefore, as well as refocusing attention from problems and limitations to competencies and strengths, researchers need to shift from broadly but shallowly surveying the First Peoples to obtaining more detailed, in-depth accounts of their experiences.

In most cultures parents are the primary caregivers. However, in First Peoples families the extended family plays a large role in raising children (Joe \& Malach, 1992; MacPhee, Fritz, \& Miller-Heyl, 1996). Kinship, emphasizing the inter-connectedness of many family members and even nonfamilial community members, is one of the fundamental traditional values of First Peoples. In addition to biological parents, the socialization of children involves grandparents, other family members, and tribal elders (Burgess, 1980; Cooke-Dallin, Rosborough, \& Underwood, 2000; LaFromboise \& Low, 1998). In fact, compared with Canadian Caucasian families, grandparents and extended families are more involved in First Peoples families and more First Peoples children live in homes with three or more generations of family members (Thompson, 2003). The family constellations of the First Peoples can also differ in other ways. For instance, infants may be reared in a separate home 
The existing research

on parenting among

First Peoples parents

has relied on traditional

social science methods

of inquiry, including

questionnaires with rating

scales. Some researchers

have questioned the

appropriateness of these

methods. As these

questionnaires were

principally developed for

use with Western cultural

groups in North America,

they may not be valid or

appropriate for use with

other cultural groups

including First Peoples. by grandparents or uncles and aunts. As youths they may continue to live with other family members, who can include third or even fifth-degree relatives (MacPhee et al., 1996; Seidman et al., 1994). A 'family' does not only consist of children with their biological parents, but includes all community members involved in socialization of children. Thus, in terms of research participants, we will need to broaden our definition of parents to include all individuals involved in child-rearing. With respect to the research process, this means that we should ask who the members of a 'family' are (family and nonblood relatives) and avoid assuming that only the biological parents comprise the family. Conversely, we also should not assume that all members of the extended family should be included. In our attempts to understand familial influences on First Peoples children's development and competence, we need to resist applying Western traditional notions of 'parents' and look for more culturally appropriate definitions of parents.

The existing research on parenting among First Peoples parents has relied on traditional social science methods of inquiry, including questionnaires with rating scales. Some researchers have questioned the appropriateness of these methods (e.g., Beiser, 1981). As these questionnaires were principally developed for use with Western cultural groups in North America, they may not be valid or appropriate for use with other cultural groups including First Peoples. The content covered in those questionnaires may not be relevant for the experiences of First Peoples. The wording of questions may contain implicit biases, be unclear, or be unfamiliar to First Peoples. The concepts of ratings scales and anchor terms (e.g., strongly disagree) have grown out of Western academics' work and may not be typical of First Peoples' thoughts and perspectives on child rearing and children's competence. Also, methods of interpreting the meaning of scores usually have been standardized on the basis of Caucasian groups who differ immensely from most First Peoples groups on a number of characteristics, thus potentially rendering all comparisons or inferences about test results inaccurate and invalid.

One might infer from this critique that researchers simply need to standardize test scores with First Peoples groups in order to use these existing questionnaires more appropriately. While that certainly would be helpful, we contend that new approaches and methods will also need to be researched. Traditional social science questionnaires should be supplemented (if not replaced) by other information gathering methods that are adapted to better match traditional First Peoples customs and values. Although common in some social science fields, narrative approaches have only recently been recognized as potentially valuable and rich sources of information by socialization researchers working within psychology. Narrative approaches allow parents to generate open-ended and self-directed accounts of their parenting practices; this may be an ideal method because First Peoples culture stresses the importance of conversation (e.g., Carbaugh, 2001). Participants' freely generated accounts of their beliefs, experiences and practices can be examined for themes and content that are directly relevant for First Peoples socialization of children. Similarly, narrative reports from parents, other family members, teachers or even children themselves may be more effective ways of identifying First Peoples children's competent development. The flexibility of narrative procedures makes them wellsuited for application to a range of topics.

One last area that will require a shift in focus is the process through which research is initiated and maintained. Standard research has been likened to a 'helicopter' process, where the researcher drops in for a quick data collection trip and is never seen again. Montour (1987, as cited in Macaulay et al., 2003) described this experience as "outside research teams 


Montour described this
experience as "outside
research teams swooped
down from the skies,
swarmed all over town,
asked nosey questions that
were none of their business
and then disappeared never
to be heard again". This
kind of researcher-initiated
approach often benefits
the researcher and his or
her academic career, but is
of little or no benefit to the
First Peoples communities.

Montour described this

experience as "outside

research teams swooped

down from the skies, swarmed all over town, asked nosey questions that were none of their business and then disappeared never to be heard again". This kind of researcher-initiated approach often benefits the researcher and his or of little or no benefit to the First Peoples communities. swooped down from the skies, swarmed all over town, asked nosey questions that were none of their business and then disappeared never to be heard again". This kind of researcher-initiated approach often benefits the researcher and his or her academic career, but is of little or no benefit to the First Peoples communities. Darou and his colleagues (Darou, Hum, \& Kurtness, 1993; Darou, Kurtness, \& Hum, 2000) describe the James Bay Cree of Québec as having endured countless negative experiences with non-Aboriginal researchers. As a result, they have ejected all but one researcher and put a moratorium on all future research in their territory. They state that this is due to the researchers' refusal to accept Cree authority, and the little perceived benefit of this research for the community. Darou, Hum, and Kurtness (2000) concluded with the following suggestions: (1) "It is entirely inappropriate to conduct research unless you have been invited in and you have a clear and relevant purpose" and (2) "It is important that your research put something valuable back into the community" (italics added; p. 52). Overall, the process of research needs to be collaborative in nature and yield some tangible outcomes that can be of benefit to the community.

\section{Culturally-Sensitive Directions for Research}

Theories regarding cultural differences in psychopathology have centered around two opposing perspectives: emic vs. etic (Dragnus \& Tanaka-Matsumi, 2003). The emic approach focuses on the culturespecific behaviour, customs, values and traditions of a specific culture group. This position has also been described as a relativist perspective. From this vantage point, researchers focus on the scope of cultural variation, the need to understand the unique phenomena within any given culture, and to study cultural groups on their own terms. This perspective is contrasted with an etic or universalist perspective which looks for universals that are 'true' across cultures and focuses on the differences in levels of certain dimensions and categories across different cultural groups.

For culturally-sensitive research to be conducted with First Peoples families, an emic approach needs to be taken. Researchers must clearly understand the culture before embarking on a research project. Douglas (1994) presented an account of her experiences in understanding schooling within an Inuit community as a first step towards recontextualizing the institution of schooling to better reflect the community context. Likewise, Gillis (1992) sought to understand First Peoples parents' views about early childhood education prior to suggesting changes to day care curriculum. These two researchers were successfully able to understand First Peoples communities prior to suggesting changes to schooling, and circumvented the use of false assumptions of First Peoples to guide their research.

A corollary point is the need to respect the heterogeneity of First Peoples. Often First Peoples are considered a homogenous group and their culture is reduced to a single entity (Gross, 1998; cited in Coleman, Unrau, \& Manyfingers, 2001). Recognizing that there are intergroup differences should not be made at the expense of recognition of intragroup differences. With over 550 recognized Native nations in the United States and over 1000 reserves in Canada, there exists considerable heterogeneity (Thomason, 1991; Weaver, 1997, 1999). Additionally, being part of a culture does not mean that all individuals subscribe to the specific values and traditions of that culture to the same degree. As Gross (1998; as cited in Coleman et al., 2001) stated "all the study in the world about a given culture or subculture might not lend a hint of explanation of the behavior or attitudes of a single member of that culture or subculture" (p. 9). Understanding First 


\author{
With the shift toward \\ Participatory Action \\ Research, recognizing \\ and promoting active \\ community participation in \\ research is replacing past \\ research models in which \\ researchers held exclusive \\ control over the process \\ and the results. Thus, it will \\ be essential to advance \\ a code of research ethics \\ that focuses greatly on \\ confidentiality, avoidance of \\ harm and potential benefits \\ at a community level.
}

Peoples at an individual, family and community level is a requisite of any research endeavours that hope to be insightful, accurate, and useful.

Working with a community is perhaps the most culturally-sensitive approach to research with First Peoples populations. In this framework for conducting research, communities are involved in an equal partnership with researcher. This method is called participatory action research (PAR) and is defined as the systematic enquiry, involving collaboration of those affected by the issue being studied and the researchers, for the purpose of education and taking action or effecting social change (Green et al., 1995). PAR is based on the integration of community members as equal partners; integration of the intervention and evaluation the intervention's success; and creation of learning experiences for the program's researchers and staff, as well as participants. A unique feature of this research perspective is the equal involvement of 3 members: (i) community researchers; (ii) academic researchers; and (iii) the community advisory board (community members). The importance of the PAR process cannot be overstated, as both research outcomes and practical knowledge transfer will contribute to First Peoples' acquisition of the information, skills and tools needed to continue advancing their own welfare.

An excellent example of the successful implementation of this research agenda in a First Peoples community in Canada is the Kahnawake Schools Diabetes Prevention Project (KSDPP; Potvin, Cargo, McComber, Delormier, \& Macaulay, 2003). Members of the Kahnawake community recognized increasing rates of diabetes as an important health concern. KSDPP was therefore founded by Kahnawake community members, working with researchers, with the goal of reducing the incidence of Type 2 diabetes amongst the First Peoples in Kahnawake. KSDPP seeks to accomplish this by implementing intervention activities for schools, families and the community that promote healthy eating, physical activity and positive attitudes about health. They conduct community-based research on these activities and report all research results back to the community. They also train community intervention workers, and academic and community researchers and individuals from other First Peoples communities to promote capacity building. Of particular significance is the adaptation of the curriculum to coincide with the values and beliefs of the Mohawk culture. This impressively demonstrates a thorough understanding of the culture, providing evidence for a successful emic approach.

\section{Ethical Considerations with First Peoples}

With the shift toward PAR, recognizing and promoting active community participation in research is replacing past research models in which researchers held exclusive control over the process and the results (Macaulay et al., 1998). Thus, it will be essential to advance a code of research ethics that focuses greatly on confidentiality, avoidance of harm and potential benefits at a community level. It is worthy to note that, correspondingly, Canadian codes of ethics (e.g., MRC, NSERC, \& SSHRC, 1998) and those of First Peoples groups (e.g., Inuit Tapirisat of Canada and Nunavut Research Institute, 1998) have grown to reflect this sharing of leadership, research design, and decision-making (Macaulay et al., 1998).

Additionally, integral to PAR is the development of a code of ethics to guide each specific research study, developed through the collaboration of the researchers and the community members. Macaulay et al. (1998) provide a useful example of the successful development of a code of research ethics applied to the KSDDP. Their code included a policy statement about the incorporation of a Mohawk perspective into the project, clarification 


A great deal is known
about Caucasian children's
healthy psychosocial
development and the
qualities of parenting that
support their competence.
Conversely, developmental
scientists working with
First Peoples cultures have
concentrated their efforts
on children's problems
and families' difficulties.
This has contributed
to an incomplete and
unrepresentative picture of
First Peoples families.

A great deal is known healthy psychosocial development and the qualities of parenting that support their competence. Conversely, developmental scientists working with First Peoples cultures have concentrated their efforts on children's problems and families' difficulties. This has contributed unrepresentative picture of First Peoples families. of the roles and obligations of the partners, and guidelines for control of data and dissemination of results. Thus, through the process of discussion and negotiation that is essential to a true partnership, the expectations, rights and responsibilities of all research collaborators were clearly and openly established.

Researchers and practitioners must also be aware of ethics on a daily level, through the ethics of personal interaction (e.g., Ellerby, McKenzie, McKay, Gariépy, \& Kaufert, 2000). Respect for the rights, and protection of the well being, of participants in research must be informed by an awareness of and sensitivity to the values and traditions of the culture in which participants live. Brant (1990) described how potential interpersonal conflicts can be avoided by utilizing First Peoples' practices of non-interference, non-competitiveness, emotional restraint, and sharing. Non-interference is rooted in maintaining deep respect for every individual's independence, such that approaching an interaction as an instructor, or attempting to persuade or coerce another person, are undesirable ways to behave. Non-competitiveness serves to minimize group rivalry, and prevents the embarrassment that a less able group member might feel in a situation that has the potential to reveal individual differences in ability. Emotional restraint promotes self-control and discourages the expression of strong emotional reactions, either positive or negative. Sharing is based on generosity and the avoidance of hoarding of goods or resources. Together, these practices emphasise respect and egalitarianism in interpersonal interactions. Researchers' use of these practices to discuss the research procedures and process, and negotiate the code of research ethics, should serve to facilitate successful and mutually beneficial interactions with the First Peoples children, families and communities involved in investigations.

\section{Concluding Remarks}

A great deal is known about Caucasian children's healthy psychosocial development and the qualities of parenting that support their competence. Conversely, developmental scientists working with First Peoples cultures have concentrated their efforts on children's problems and families' difficulties. This has contributed to an incomplete and unrepresentative picture of First Peoples families. Researchers should approach First Peoples communities with the goal of understanding the culture, by taking an emic approach. This process should be done by developing meaningful relationships between academics, researchers, and community members before proceeding with research, and maintaining this collaboration through all stages of the research process. The majority of children in First Peoples communities are healthy and competent and do not have psychological problems. Redirecting our research efforts towards focusing upon the strengths of families and children, and using procedures that are appropriate and sensitive to the values and traditions of the First Peoples, will be essential for obtaining a more balanced and accurate understanding of socialization and development within these communities.

\section{References}

Ainsworth, M. S., Blehar, M. C., Waters, E., \& Wall, S. (1978). Patterns of attachment: A psychological study of the strange situation. Oxford, England: Lawrence Erlbaum.

Barber, B. K., \& Harmon, E L. (2002). Violating the self: Parental psychological control of children and adolescents. In B. K. Barber (Ed.), Intrusive parenting: How psychological control affects children and adolescents, (pp. 5396). Washington, DC: American Psychological Association. 
Baumrind, D. (1971). Current patterns of parental authority. Developmental Psychology, 4, pp. 1-103.

Beiser, M. (1981). Mental health of American Indian and Alaska Native children: Some epidemiological perspectives. White Cloud Journal, 2(2), pp. 37-47.

Brant, C. C. (1990). Native ethics and rules of behaviour. Canadian Journal of Psychiatry, 35, pp. 534-539.

Bronfenbrenner, U. (1979). The ecology of human development: Experiments by nature and design. Cambridge, MA: Harvard University Press.

Bronfenbrenner, U. (1989). Ecological systems theory. In R. Vasta (Ed.), Annals of child development, (Vol. 6, pp. 187-251). Greenwich, CT: JAI Press.

Bronfenbrenner, U. (1993). The ecology of cognitive development: Research models and fugitive findings. In R. H. Wozniak \& K. W. Fischer (Eds.), Development in context (pp. 3-44). Hillsdale, NJ: Erlbaum.

Burgess, B. J. (1980). Parenting in the Native-American community. In M. D. Fantini \& R. Cárdenas, (Eds.), Parenting in a multicultural society, (pp. 63-73). New York: Longman.

Carbaugh, D. (2001). "The people will come to you": Blackfeet narrative as a resource for contemporary living. In J. Brockmeier \& D. Carbarugh (Eds.), Narrative and identity: Studies in Autobiography, Self and Culture. Studies in Narrative (pp. 103-127). Philadelphia, PA: John Benjamins.

Carson, D. K., Chowdhury, A., Peery, C. K., \& Pati, C. (1999). Family characteristics and adolescent competence in India: Investigation of youth in southern Orissa. Journal of Youth and Adolescence, 28, pp. 211233.

Chen, X., Hastings, P.D., Rubin, K.H., Chen, H., Cen, G., \& Stewart, S.L.
(1998). Child-rearing attitudes and behavioral inhibition in Chinese and Canadian toddlers: A cross-cultural study. Developmental Psychology, 34(4), pp. 677-686.

Chen, X., Li, D., Li, Z.-y., Li, B.-s., \& Liu, M. (2000). Sociable and prosocial dimensions of social competence in Chinese children: Common and unique contributions to social, academic, and psychological adjustment. Developmental Psychology, 36, pp. 302-314.

Coleman, H., Unrau, Y. A., \& Manyfingers, B. (2001). Revamping family preservation services for Native families. Journal of Ethnic and Cultural Diversity in Social Work, 10, pp. 49-68.

Connors, J.L., \& Donnellan, A.M. (1998). Walk in beauty: Western perspectives on disability and Navajo family/ cultural resilience. In H.I. McCubbin, E.A. Thompson, A.I. Thompson, \& J.E. Fromer (Vol. Ed.), Resiliency in Families Series : Vol. 2. Resiliency in Native American and Immigrant Families (pp. 159-182). Thousand Oaks, CA: Sage.

Cooke-Dallin, B., Rosborough, T., \& Underwood, L. (2000). The role of elders in child and youth care education. Journal of Native Education, 24, pp. 82-91.

Cowan, P. A., Cowan, C. P., Schulz, M., \& Heming, G. (1994). Prebirth to preschool family factors predicting children's adaptation to kindergarten. IN R. Parke \& S. Kellam (Eds)., Exploring family relationships with other social contexts: Advances in family research (Vol. 4, pp.75-114). Hillsdale, NJ: Erlbaum.

Darou, W., Hum, A., \& Kurtness, J. (1993). An investigation of the impact of psychological research on a Native population. Professional Psychology: Research and Practice, 24, pp. $325-$ 329. 


\section{First Peoples Child \& Family Review, Volume 1, Number 1, 2004}

Darou, W., Kurtness, J., \& Hum, A. (2000). The impact of conducting research with a First Nation. Canadian Journal of Counselling, 34, pp. 43-54.

Denham, S. A., Workman, E., Cole, P. M., Weissbrod, C., Kendziora, K. T., \& Zahn-Waxler, C. (2000). Prediction of externalizing behavior problems from early to middle childhood: The role of parental socialization and emotion expression. Development and Psychopathology, 12, pp. 23-45.

Deyhle, D., \& LaCompte, M. (1999). Cultural differences in child development: Navajo adolescents in middle schools. In R. H. Sheets \& E. R. Hoolins (Eds.), Racial and ethnic identity in school practices: Aspects of human development (pp.123-139). Mahwah, NJ: Lawrence Erlbaum.

Dishion, T. J., \& Patterson, G. R. (1997). The timing and severity of antisocial behavior: Three hypotheses within an ecological framework. In D. M. Stoff \& J. Breiling Eds), Handbook of antisocial behavior, (pp. 205-217). New York, John Wiley \& Sons, Inc.

Douglas, A. S. (1994). Recontextualizing schooling within an Inuit community. Canadian Journal of Education, 19, pp. 154-164.

Dragnus, J. G., \& Tanaka-Matsumi, J. (2003). Assessment of psychopathology across and within cultures: Issues and findings.

Behaviour Research and Therapy, 41, pp. 755-776.

Ellerby, J. H., McKenzie, J., McKay, S., Gariépy, G. J., \& Kaufert, J. M. (2000). Bioethics for clinicians: 18. Aboriginal cultures. Canadian Medical Association Journal, 163(7), pp. 845-850.

Garmezy, N. (1974). The study of competence in children at risk for severe psychopathology. IN E. J. Anthony \& C. Koupernik (Eds.), The child in his family: Vol. 3. Children at psychatric risk (pp. 77-97). New York: Wiley.

Gillis, J. (1992). Views of Native parents about early childhood education. Canadian Journal of Native Education, 19, pp. 73-81.

Glover, G. (2001). Parenting in Native American families. In N.B. Webb (Ed.), Culturally Diverse ParentChild and Family Relationships: A Guide for Social Workers and Other Practitioners, (pp. 205-231). New York: Columbia University Press.

Gotowiec, A., \& Beiser, M. (1993). Aboriginal children's mental health: Unique challenges. Canada's Mental Health, 94, pp. 7-11.

Gray, M., \& Steinberg, L. (1999). Unpacking authoritative parenting: Reassessing a multidimensional construct. Journal of Marriage and the Family, 61, pp. 574-587.

Green, L. W., George, M. A., Daniel, M., Frankish, C. J., Herbert, C. J., Bowie, W. R., et al. (1995). Participatory research in health promotion. Ottawa, Ontario: The Royal Society of Canada.

Grusec, J. E., \& Ungerer, J. (2003). Effective socialization as problem solving and the role of parenting cognitions. In L. Kuczynski (Ed.), Handbook of dynamics in parent-child relations (pp. 211-228). Thousand Oaks, CA: Sage Publications.

Hastings, P. D., Zahn-Waxler, C., Robinson, J., Usher, B., \& Bridges, D. (2000). The development of concern for others in children with behavior problems. Developmental Psychology, 36, pp. 531-546.

Hoffman, M. (1977). Moral internalization: Current theory and research. In L. Berkowitz (Ed.), Advances in experimental social psychology. New York: Academic Press.

Inuit Tapirisat of Canada and Nunavut Research Institute (1998). Negotiating research relationships: A guide for 
communities. Ottawa, Canada: Inuit Tapirisat of Canada.

Jambunathan, S., \& Counselman, K. P. (2002). Parenting attitudes of Asian Indian mothers living in the United States and in India. Early Child Development and Care, 172, pp. 657662.

Joe, J. R., \& Malach, R. S. (1992). Families with Native American roots. In E. W. Lynch and M. J. Hanson (Eds.), Developing cross-cultural competence: A guide for working with children and families (1st Ed., pp. 89-119). Baltimore: Paul H. Brookes Publishing Co.

Kallam, M. \& Coser, P. G. (1994). Native Americans and behavioral disorders. In R. L. Peterson \& S. Ishii-Joran (Eds.), Multicultural issues in the education of students with behavioral disorders (pp. 126-137). Cambridge, MA: Brookline Books.

Kuczynski, L., \& Kochanska, G. (1990). Development of children's noncompliance strategies from toddlerhood to age 5. Developmental Psychology, 26, pp. 398-408.

LaFromboise, T. D., \& Low, K. G. (1998). American Indian children and adolescents. In J. T. Gibbs, L. N. Huang, \& Associates (Eds.), Children of color: Psychological interventions with culturally diverse youth (pp. 112142). San Francisco: Jossey-Bass.

Macaulay, A. Cargo, M., McGregor, A., Norton, L., Diabo, T., Salmon, L., et al. (2003, June). Introduction to the theory and practice of participatory research. Presentation made at the Ethics and Practice of Participatory Community Research Workshop, Kahnawake, Québec, Canada.

Macaulay, A., Delormier, T., McComber, A. M., Cross, E. J., Potvin, L. P., Paradis, G., et al. (1998). Participatory research with Native community of
Kahnawake creates innovative code of research ethics. Canadian Journal of Public Health, 89(2), pp. 105-108.

Maccoby, E. E., \& Martin, J. A. (1983). Socialization in the context of the family: Parent-child interaction. In E. M. Hetherington (Ed.), P. H. Mussen (Series Ed.), Handbook of child psychology: Vol. 4 Socialization, personality, and social development (pp. 1-101). New York: Wiley.

Macdonald, K. (1992). Warmth as a developmental construct: An evolutionary analysis. Child Development, 63, pp. 753-773.

MacMillan, H., Welsh, C., Jamieson, E., Crawford, A., \& Boyle, M. (2000). Children's health. First Nations and Inuit regional health surveys, 2000. Ottawa, ON: Assembly of First Nations.

MacMillan, H. L., Boyle, M. H., Wong, M. Y.-Y., Duku, E. K., Fleming, J. E., \& Walsh, C. A. (1999). Slapping and spanking children in childhood and its association with lifetime prevalence of psychiatric disorders in a general population sample. Canadian Medical Association Journal, 161, pp. 805-809.

MacPhee, D., Fritz, J., Miller-Heyl, J. (1996). Ethnic variation in personal social networks and parenting. Child Development, 67, pp. 3278-3295.

Main, M., \& Solomon, J. (1990). Procedures for identifying infants as disorganized/disoriented during the Ainsworth Strange Situation. In M. T. Greenberg \& D. Cicchetti (Eds.), Attachment in the preschool years: Theory, research, and intervention (pp. 121-160). Chicago, IL: University of Chicago Press.

Masten, A. S., \& Coatsworth, J. D. (1998). The development of competence in favourable and unfavourable environments: Lessons from research on successful children. American Psychologist, 53, pp. 205-220. 


\section{First Peoples Child \& Family Review, Volume 1, Number 1, 2004}

Masten, A. S. (2001). Ordinary magic: Resilience processes in development. American Psychologist, 56, pp. $227-$ 238.

Mattanah, J. F. (2001). Parental psychological autonomy and children's academic competence and behavioral adjustment in late childhood: More than just limitsetting and warmth. Merrill-PalmerQuarterly, 47, pp. 355-376.

McShane, K. (2003). The New Friends Vignettes: A new measure for assessing overprotective parenting in parents of anxious preschoolers. Unpublished master's thesis, Concordia University, Montréal, Québec, Canada.

Medical Research Council of Canada, Natural Sciences and Engineering Research Council of Canada, Social Sciences and Humanities Research Council of Canada (1998). Tri-council policy statement: Ethical Conduct for research involving humans. Ottawa, ON: Public Works and Government Services Canada.

Patterson, G. R., Reid, J. B., \& Dishion, T. J. (1992). Antisocial boys. Eugene, OR: Castalia.

Paulson, S. (1994). Relations of parenting style and parental involvement with ninth-grade students' achievement. Journal of Early Adolescence, 14, pp. 250-267.

Potvin, L., Cargo, M., McComber, A. M., Delormier, T., \& Macaulay, A. C. (2003). Implementing participatory intervention and research in communities: Lessons from the Kahnawake Schools Diabetes Prevention Project in Canada. Social Science and Medicine, 56, pp. 1295 1305 .

Radke-Yarrow, M., \& Zahn-Waxler, C., (1984). Roots, motives and patterns in children's prosocial behavior. In J. Reykowski, J. Karylowski, D.,
Bar-Tel, \& E. Staub (Eds.), The development and maintenance of prosocial behaviors: International perspective on positive morality (pp. 81-99). New York: Plenum.

Rohner, E. C., Chaille, C., Rohner, R. P. (1980). Perceived parental acceptancerejection and the development of children's locus of control. The Journal of Psychology, 104, pp. 83-86.

Rubin, K.H., Burgess, K.B., \& Hastings, P.D. (2002). Stability and socialbehavioral consequences of toddlers' inhibited temperament and parenting behaviors. Child Development, 73, pp. 483-495.

Rutter, M. (1979). Protective factors in children's responses in stress and disadvantage. In M. W. Kent \& J. E. Rolf (Eds.), Primary prevention of psychopathology: Vol. 3. Social competence in children (pp.49-74). Hanover, NH: University of New England Press.

Saarni, C. (1999). The development of emotional competence. New York: Guilford Press.

Seidman, R. Y., Williams, R., Burns, P., Jacobson, S., Weatherby, F., \& Primeaux, M., (1994). Culture sensitivity in assessing urban Native American parenting. Public Health Nursing, 11, pp. 98-103.

Smith, L. T. (1999). Decolonizing methodologies: Research and Indigenous peoples. New York, NY: Zed Books Ltd.

Steinberg, L. D., Lamborn, S. D., Darling, N., Mounts, N. S., \& Dornbusch, S. M. (1994). Over-time changes in adjustment and competence among adolescents from authoritative, authoritarian, indulgent and neglectful families. Child Development, 65, pp. 754-770.

Strauss, J. H. (1995). Reframing and refocusing American Indian family strengths. In C. K. Jacobson (Ed.), 
Culturally Senstive Approaches to Research on Child

Development and Family Practices in First Peoples' Communities

American families: Issues in race and ethnicity (pp.105-118). New York:

Garland Publishing.

Straus, M. A., \& Donnelly, D. A. (1994).

Beating the devil out of them:

Corporal punishment in American families. New York: Lexington Books/ Macmillan Inc.

Thomason, T. C. (1991). Counseling Native Americans: An introduction for non-Native American counselors. Journal of Counseling and Development, 69, pp. 321-327.

Thompson, E. (2003, December 10). 930,000 Canadians live in threegeneration households. The Montreal Gazette, p. A13.

Weaver, H. N. (1997). The challenges of research in Native American communities: Incorporating principles of cultural competence. Journal of Social Service Research, 23, pp. 1-15.

Weaver, H. N. (1999). Health concerns for Native American youth: A culturally grounded approach to health promotion. Journal of Human Behavior in the Social Environment, 2, pp. 127-143.

Weinfield, N.S., Sroufe, L. A., Egeland, B., \& Carlson, E. A. (1999). The nature of individual differences in infantcaregiver attachment. In J. Cassidy \& P.R. Shaver (Eds.), Handbook of attachment: Theory, research and clinical applications (pp.68-88). New York: The Guildford Press.

Zitzow, D. (1990). Ojibway adolescent time spent with parents/elders as related to delinquency and court adjudication experiences. American Indian and Alaska Native Mental Health Research, 4, pp. 53-63. 